resolved the paradox that the current age was smaller than the age of the Earth. His work on the Magellanic Clouds also showed that they were a mixture of both old and young stars contrary to earlier suppositions. In contrast his work on the Sculptor Galaxy was largely responsible for establishing that such spheroidal galaxies consisted entirely of old stars. With his collaborators he made extensive spectroscopic studies of stars in the Magellanic Clouds. This established an upper limit to stellar brightness at about a million times the solar luminosity. Stars at this limit showed evidence of instability. Again with his collaborators, extensive radial velocity measurements were made in Pretoria of stars in the Southern Milky Way. This led to new determinations of the constants of galactic rotation and an estimate of the distance to the galactic centre.

Although active in many fields David Thackeray regarded himself primarily as a stellar spectroscopist and his knowledge of this field was encyclopaedic. He was particularly interested in objects with unusual spectra and the significance of this work is only slowly being realised. Thus his investigations over many years of the eclipsing symbiotic star AR Pav is a major clue to the understanding of symbiotic stars. His main legacy in this field is his studies extending over nearly 30 years of the enigmatic exploding object Eta Carinae and the slow nova RR Telescopii. In these objects he identified forbidden emission lines not yet produced in the laboratory and his detailed studies must form the basis of any theory of these puzzling objects. His discovery of strong polarisation in the halo around Eta Carinae is of particular importance.

David Thackeray approached observations with an open mind and complete integrity; refusing to draw any conclusions which were not completely justified. He was remarkably observant and rarely failed to notice an interesting feature in a spectrum even on a brief examination (often in the darkroom when the plate was still washing). In 1949 he noted visually with the $1.9 \mathrm{~m}$ telescope variation in brightness of VV Pup on a time scale of seconds. This seemed hardly credible at the time but 20 years later the result was fully confirmed using high speed photometers and is an important property of cataclysmic variables.

David was an enthusiastic observer of all natural phenomena and published a number of notes on them. The last of these on 'Dust-Devils and Spray-Devils' was published in October 1977. It was, in fact, a violent dust devil that overturned the vehicle in which he was a passenger on February 21. He had completed a successful week's observing with the $1.9 \mathrm{~m}$ telescope at Sutherland and was returning to Cape Town. He was killed instantly.

He more than any other single person opened up the Southern Hemisphere to modern astrophysics. His work was done quietly and without publicity but it has established his name at the very front of international astronomy.

Astronomers throughout the world will remember David's kindness, courtesy and humour. Many were privileged to enjoy the hospitality of David and Mary and their children in a home where astronomy blended naturally with music. He particularly welcomed and helped the many young British astronomers who came to work in Pretoria and in this way he made an important contribution to the development of astronomy in the United Kingdom.

Long a Fellow of the Royal Astronomical Society (London) he was elected an Associate a few days before his death; the first British subject to be accorded this honour. The news was waiting his return to Cape Town.

M. W. Feast

\section{Victor Eyles}

DR VICTOR EYLES, F.R.S.E., who died on 8 March 1978 at the age of 82 was the leading British historian of geology and one of the world's most eminent workers in this field.

He was a native of Bristol and after service during the first world war, first with the Royal Engineers and later as Observer with the Kite Balloons of the Royal Flying Corps, he graduated in 1920 in petrology at Bristol University. He had a long and distinguished career with the Geological Survey of Great Britain (1920-1955). In the years before the war he worked in Scotland and Northumberland making notable contributions to our knowledge of the Carboniferous sedimentary and igneous rocks of Ayrshire and Renfrewshire and the ancient crystalline (Moine) schists of the West Highlands.

In 1940 he was selected to report to the Non Ferrous Ores Committee of the Ministry of Supply on the bauxite deposits associated with Tertiary lavas of Antrim, Northern Ireland, and was later commissioned by the Ministry of Aircraft Production to carry out an extensive programme of exploration by boring. This proved 750,000 tons of bauxite, which, though rich in iron, was of commercial grade. By 1944 about 250,000 tons of the bauxite had been mined, and this produced 35,000 tons of aluminium for British aircraft, freeing valuable shipping space for the import of other essential raw materials. After the war Eyles was based in the London Office of the Geological Survey, in charge of the field units working in the Midland and South Wales Coalfields.

Dr Eyles' eminence as a historian of geology springs from a number of deeply researched bio-bibliographical articles on pioneer geologists and their work. Outstanding examples are the paper on Hutton's original statement of the Theory of the Earth and his detailed account of the Swiss geologist, L. A. Necker. Eyles was instrumental in securing the eventual publication of Necker's map of Scotland, which had been completed in manuscript in 1808 . Other early geologists whose work has been described by Eyles are J. MacCulloch, Robert Jameson, Sir James Hall and A. G. Werner. Together with his wife, Joan, he wrote a most valuable account of William Smith's great geological map of England and Wales. He also contributed some excellent general articles on the history of science, such as his account of the history of scientific activity in the Bristol region, presented at the British Association's Bristol meeting in 1955. More recently he outlined suggestions for further research in the history of geology in an article published in History of Science in 1966, and a summary of his detailed knowledge of the state of eighteenth century geology was set forth in the New Hampshire Symposium published in 1969.

Eyles' interest in the history of his science was greatly stimulated by the fine collection of early geological maps and texts which he and his wife built up over the years. Between 1951 and 1956 he gave courses on the history of geology at University College London, and he lectured at several universities in the USA. He was the United Kingdom representative on the International Committee on the History of Geological Sciences from 1967 to 1972 and was an honorary member of the Society for the Bibliography of Natural History.

Victor Eyles was a man of very few words, every one of which was well chosen. He was one of the most courteous and considerate of men with a wonderfully dry sense of humour, and was prepared to spend almost endless time in providing guidance to others in his chosen field of study. He was definitely a geologist turned historian of geology and his knowledge of both these aspects has made him the doyen of historians of geology in the British Isles. 